The inspection took place twelve hours after death. When the lungs were brought to view, they presented a greyish coloux anteriorly, but in all other parts the tints were deeper and the organs much congested, particularly about the upper and lower lobes. There was much emphysema, and a frothy mucus, with a sanguineous tinge, readily escaped on sections being made. No tubercular deposit was detected in either lung, but the pulmonary vessels, on being opened, gave exit to a large quantity of blood, and the bronchi were greatly dis. tended with mucous secretion. The heart, pericardium, and great vessels, having been removed from the chest, were found to weigh seventeen ounces and a half; the heart alone, when well washed, weighed thirteen ounces. The pericardium was pale, perfectly smooth, and free from any adhesion or deposit of lymph; it presented no deviation from the normal condition, and held about ten drachms of pale straw-coloured serum.

The heart was found of a some what larger size than is usual, considering the patient's age and sex; it was covered with much fat, particularly at the base and posterior surface, and the muscular structure was rather pale, softened, and lax; the ventricles, especially the right one, contained large and firm fibrinous deposits, sending processes to the different vessels in connexion with the heart. These fibrinous masses were very inelastic, they broke readily asunder, and had a granular texture. The columnæ cornex of the left ventricle appeared enlarged; the mitral valves slightly thicker than usual, but they were free from any deposit. 'The semi-lunar valves of the aorta seemed quite unchanged, slightly opaque, but free from roughness.

On examining the abdomen the liver was found hypertro. phied, the colour normal, but the organ much congested; it weighed four pounds. No alteration of importance was discovered in the other abdominal viscera; the ovaria, however, were enlarged, and the right contained a perfect Graafian vessel in its interior, and four small and translucent cysts, not exceeding the size of a pea, were developed on its surface. The left ovarium was studded in a similar manner by six or seven small cysts, and between the fimbriated extremity of the Fallopian tube and right ovarium, was situated a cyst of the size of a nutmeg, fllled with a transparent, pale, strawcoloured fluid.

The calvarium having been raised, the dura mater was seen thickened and firmly adherent to the posterior part of the skull; the arachnoid presented no alterations; its vessels were, however, somewhat congested. The cerebral substance was healthy and firm, it did not offer any trace of congestion, and none of the cavities of the brain presented any abnormal appearances.

Here, then, were witnessed an intense amount of cardiac disturbance, delirium, coma, convulsions, and death, with hardly any of those pathological changes which, on inspection, we generally look for in similar cases. Or shall we consider the ten drachms of serous fluid found in the pericardium as an event of inflammation? This position is hardly tenable, and in lieu of it might we not with some reason look upon the cardiac phenomena as a sudden metastasis of the rheumatic inflammation upon an organ already in a state of slight hypertrophy, which inflammation produced an effect on the cerebral mass, which has been noticed in several other cases? The patient sank under the attack, and so rapidly that tangible traces of inflammation were not discovered in the heart, though it is evident, looking at the symptoms of the sudden seizure, that such inflammation must have existed, and was mainly instrumental in the fatal result.

\section{ON CONCUSSION OF THE BRAIN.}

\section{BY J. INGHAM IKIN, Esq., M.R.C.S., L.S.A., Leeds.}

From perusing the Mirror of the Practice of Medicine and Surgery, and the notice of interesting cases it contains, I am reminded of a few cases that have fallen under my care, a slight notice of which may perhaps be worth recording in THE LANCET. From either carelessness or want of leisure, most surgeons are apt to refer to hospital reports for the perusal of cases, rather than be at the trouble of transcribing those that happen in their own practice. Hence, as has of tep been stated, much valuable matter and statistical information as to the result of disease or accident, is withheld from the profession. Whilst kept in suspense by a wearisome midwifery case, I write out a few that readily recur to my mind, which are not altogether devoid of interest. In one of your late numbers there was a notice of some cases of concussion of the brain: I will briefly state the general particulars of thiree or four cases.
Now it has often been stated, when speaking or writing on accidents to the head, and their various symptoms, that discharge of blood from the ears is a symptom that indicates fracture of the base of the cranium. That this is often the case is doubtless correct, but that it is so invariably may be justly questioned.

CASE 1.-Mr. R-, about twenty-five years of age, a healthy, fine young man, was thrown out of his gig by his horse running away and dashing against a heap of stones. He was taken up insensible and carried home. He continued uncorscious for some hours; his face was much bruised and cut, and the scalp severely wounded by the sharp edges of stone he had fallen against; there was a discharge of blood from both ears, which continued in small quantities for two or three days. Fracture of the skull was suspected at first, but could not be detected. On recovering the shock he complained of misty vision, had great intolerance of light, pain in the head, and vomited from time to time during the night following the accident. Tbe next day the symptoms of reaction were such as to call for bleeding with two dozen leeches, the application of mustard cataplasms to the back of the neck, the administration of an effective purgative, and an antimonial saline. He was kept in a dark room, and perfectly quiet for about ten days, and at the end of a fortnight all alarming symptoms subsided, and in three weeks he was discharged, with the caution to apply to me on the slightest return of the sickness, dimness of vision, or pain in the head. With the exception of ordering an occasional aperient, he did not require further treatment, as the wounds healed kindly, and, I must add, he attended most strictly to my injunctions as to his diet and the avoidance of stimulants \&c.

CASE 2.-Mr. - a cavalry officer, a tall, stout young man, weighing between thirteen and fourteen stone, was thrown out of a tilbury, by his horse taking fright and running against the gate-post of the barrack-yard; he was thrown out, and pitched on his head and shoulder. The result was concussion of the brain, contusion of the shoulder-joint, and fracture of the clavicle. The concussion of the brain displayed itself by insensibility, which did not, however, continue above half an hour, and during the evening the pulse rose to near a hundred, and he became hot, irritable, and restless. He was now bled in the arm, took a purgative, and had his feet put into hot water mixed with mustard. The clavicle was not bandaged. till next day, as from the swelling and pain in the shoulder it required fomentation for some time, and it was not desirable to apply bandages till some hours had elapsed. For two or three days the head symptoms continued alarming-pain, intolerance of light, \&c. These, however, gradually subsided, and no danger was apprehended, and $I$ discontinued seeing him, though he was still under the care of the surgeon of the regiment, absent at the time I first saw him.

I heard afterwards that he was an imprudent young man, and difficult to manage, though he completely recovered, it was thought, from the effects of his accident, but that about nine months after it, he got leave of absence to visit his relations at Devonport, took a short trip by sea, was violently sea-sick, and died comatose from the effects a few days after landing. We may fairly infer that serious injury had happened to the brain from his fall, and that the congestion and straining from the sea-sickness acted upon a material already injured and shaken by the previous concussion. I never heard whether a post-mortem examination took place or not.

CASE 3.-A gentleman riding home one dark night at a good pace, came suddenly upon some sheep resting on the road; his horse fell, and the rider was thrown with considerable violence on his head; he was removed to a cottage at the roadside, and I was sent for. I found him cold, totally insensible, pupils dilated, pulse scarcely perceptible, a wound of the scalp just above and behind the ear; there was a discharge of bloody froth from his mouth, and his appearance was altogether most deathly and alarming. His limbs were not injured. A warm cordial was given, or rather poured down the throat, ammonia applied to the nose, gentle friction made on the feet and legs, and the body wrapped in a warm blanket. The propriety of moving him was the difficulty to my mind, but after reflection, and waiting till the body was warm and the pulse had returned, I decided it would be safer to run the risk of an immediate removal than defer it till re-action was fairly established, and the shaking of a carriage would bo more acutely felt; he was therefore removed to his residence abont five miles distant. At the expiration of six hours he became conscious, but the pain in his head, the tendeney to sleep, and to speak incoherently, vomiting, intolerance of noise 
light, or being touched in any way, continued for above forty. eight hours, and some of these symptoms for four or five days. He was bled with leeches, freely purger, and as soon as the vomiting discontinued, took antimonial salines. In the way of food he had little or nothing for the first week, nor did he ask for anything except a drink of tea or toast-and-water. The head symptoms gradually subsided, though his recovery was tedious and his restoration to health not perfect for above two years from the time of the accident, as the frequent return during that time of attacks of sickness, headache, and irritability plainly indicated; perfect quiet, leeches, aperients, and counter-irritation had to be resorted to from time to time. Ultimately, every unfavourable symptom subsided, and he is now apparently a strong man.

The long duration and the frequent return of these head symptoms for so long a period after the accident, induce me to think that this was something more than a case of simple concussion. We know, from experience and from the publication of many striking cases, that injuries to the head, blows, falls, \&c., though apparently recovered from, may and do often produce some lesion of the cerebrum, which, though it may lie comparatively dormant for years, ultimately brings on a fatal attack, and on examination of the brain after death, morbid thickening of its coverings, abscess, effusion, a blood or apoplectic cyst, or softening of its structure, may be found to exist.

CASE 4-Mr. G- M.P. on taking a fence of post and rails, while hunting, fell on his head, and his horse upon him. I happened to be close at hand, (for I must admit I am not one of those who would abolish this noble sport, or purposely avoid it, or consider it more worthy of censure than fishing, shooting, or any other innocent relaxation; for relaxation must be taken, by all, in one form or another, and is taken often in a much less blameless mode than in an occasional day's hunting in a well-regulated and gentlemanly field.*) I saw him almost directly, just in time to save him much torture from our officious friends, about " to pull his neck in," "put him on his legs," "pour brandy down his throat," and adopt other active measures for his relief, as they thought. Speaking of "pulling necks in," I cannot refrain from naming an amusing but rather awkward circumstance, which happened to a friend of my own. He was in the habit of hunting, but unfortunately had a very bad figure-was short, had high shoulders, a peculiarly short neck, and rather a hump-back. One day he had a fall, and lay for a moment or two helpless on the ground, when two of the field came to his assistance, and set to work to give him relief, one pulling his legs, the other his head, thinking to pull his back straight, and " his neck in," when the discomforted and helpless, crooked little Nimrod exclaimed, "For God's sake let me alone; I was born so,"much to the wonder of his sympathizing friends, who rather tardily discontinued their aid.

But to the case in hand. Mr. G- was insensible, and continued so for above an hour-cold, almost pulseless. $\mathrm{He}$ had received a blow from the horse on his head, as well as the shake from the fall: the blow of the horse's shoe was to be seen on his scalp, for it had cut through his hunting-eap, which had doubtless saved his life. I let him remain on the ground some time, just supporting his head a little, wrapping his body and feet in a coat some one was kind enough to lend, untied his neckeloth, and then poured gently a little win into his throat, but found it was useless, as he made no effort to swallow. After a lapse of near an hour, we got a carriage, and removed him to the nearest residence, when he was put to bed, wrapped in hot blankets, and was able to take a little negus. Not being willing to remain at a stranger's, though he would have had every comfort and necessary attendance, I removed him, in an easy carriage, some seven or eight miles, to the friend's house where he was visiting: for I may add, he represented a southern county, and was only on a visit in Yorkshire; and hunting with strangers, he was very anxious to ride forward and distinguish himself; indeed, it had been remarked, he was "too keen," and was sure to have a "spill" before the day was over; and so it happened. During his removal, he fainted twice, and took a little brandy-and-water He passed a sleepless night, full of pain, and could scarcely move, as his shoulder was much contused, and his sides tender to the touch; indeed, I suspected, though I could not satisfactorily ascertain, that one or two of his ribs were broken, for he could not bear a minute examination of them, and $I$ was

* Sir A. Cooper was fond of field sports. Liston loved a day's hunting, and, as is well known, was in the habit of hunting regularly in Scotland. some amusing anecdotes are told of him. mere uneasy about the head symptoms than anything else. Next day he was bled freely with leeches, took a purgative and a saline, and was kept in a dark room, on the lowest possible diet. For two or three days he saw objects either double or indistinctly, and his hearing was painfully acute, with a sensation of a "whizzing in his ear;" but at the expiration of a week all these symptoms had left him, and he was comparatively well, with the exception of his inability to dress himself, from his contused shoulder and the bruised state of the muscles of his arm and back. He left for the south at the end of the week, as he was obliged, from his engagements, to do so, not of course perfectly well, but sufficiently recovered to travel. I heard afterwards, that about a year after his visit in Yorkshire, he took what was described to me as a form of low fever, and that he died after a short illness. I never have been able to hear the precise particu. lars or symptoms of his fatal illness, or whether a post-mortem examination was made.

Sept. 1851.

\section{MEDICINA MECHANICA.} BY ISAAC PIDDUCK, M.D.

A BARRISTER complained of numbness in the anterior and middle part of the right thigh. The numbness had existed about four months, sometimes more and sometimes less perceptible, but never entirely removed, giving rise, in the patient's mind, to the fear of paraplegia, or, as he termed it, the barrister's paralysis. As he had formerly suffered from spasmodic stricture and hæmorrhage into the bladder, from passing the catheter, it was supposed that the numbness might be symptomatic of some morbid condition of the urino-genital organs; but only negative replies were elicited by inquiries directed to ascertain that point.

As he was suffering from febrile catarrh, a purgative pill and a sudorific draught were prescribed. From the operation of these remedies some relief from the numbness was obtained; but in two days it returned in its former degree. It occurred to me, knowing that the occupation of my patient was sedentary, that the numbness might be entirely local, occasioned by sitting in some particular position. On requesting him to show me how he sat at his writing-table, I saw instantly how the numbness had been produced and perpetuated from day to day; for instead of sitting opposite, he sat sideways to his table. This position threw the principal weight of his body on the cutaneous branches of the sciatic nerve; and hence the local numbness was clearly traced to partial pressure; and this was further confirmed by a sensation of a glow of warmth following the numbness, after the pressure was removed.

This case is not recorded for the sake of anything extraordinary, either in its nature or its treatment, but for the very opposite reason-the frequency of the cause, and the simplicity of its cure. In anomalous affections of the nerves, unattended by disorders of health, careful investigation frequently leads to a discovery both of the disease and its remedy. The shoemaker, for instance, may suffer from constant gastralgia, owing to the pressure of the last on the epigastric region. The scribe may suffer from pain in the left hypochondriac region, from pressure against the desk. Pain may be felt in the knee-joint from pressure of a garter. Headache may arise from occupations occasioning a constant drag upon the cervical region by the prone position of the head, as in milliners and other needlewomen. Pains and loss of power and sensibility may be felt in the arms and hands, by sleeping on the back, with the arms crossed over the head. Pains and loss of power may be produced in the fingers and wrist by grasping the pen too firmly in writing. This generally happens to persons whose handwriting is good, but whose hand has become unsteady: the firm grasp of the pen is for the purpose of steadying the hand. It is probable that to this canse-viz., holding the brush -more than to the poison of lead, the wristdrop of house-painters may be owing. Pains in the larynx and hoarseness of voice may be occasioned by reading aloud and preaching, with the head bending over the book or manuscript. Cases of this kind are of frequent occurrence; they are intractable to remedies, but speedily cease on avoiding the exciting cause.

Montagu-street, Russell-square, Sept. 1851.

Appointment. - On Monday last, Mr. Robert Hamilton, late House-Surgeon of the Royal Westminster Ophthalmic and Charing-cross Hospitals, was elected one of the Honorary Surgeons to the Northern Dispensary, Liverpool. 